\title{
ZnO-nanostructure-based electrochemical sensor: Effect of nanostructure morphology on the sensing of heavy metal ions
}

\author{
Marina Krasovska*, Vjaceslavs Gerbreders, Irena Mihailova, Andrejs Ogurcovs, \\ Eriks Sledevskis, Andrejs Gerbreders and Pavels Sarajevs
}

Open Access

\author{
Full Research Paper \\ Address: \\ G. Liberts' Innovative Microscopy Centre, Institute of Life Sciences \\ and Technology, Daugavpils University, Daugavpils LV-5401, Latvia \\ Email: \\ Marina Krasovska* - marina.krasovska@du.Iv \\ * Corresponding author \\ Keywords: \\ cadmium; electrochemical sensors; heavy metal ions; lead; \\ one-dimensional nanostructures; $\mathrm{ZnO}$
}

Beilstein J. Nanotechnol. 2018, 9, 2421-2431.

doi:10.3762/bjnano.9.227

Received: 21 April 2018

Accepted: 22 August 2018

Published: 11 September 2018

Associate Editor: J. M. van Ruitenbeek

(C) 2018 Krasovska et al.; licensee Beilstein-Institut.

License and terms: see end of document.

\begin{abstract}
$\mathrm{ZnO}$ nanostructures are promising candidates for use in sensors, especially in electrochemical sensors and biosensors, due to their unique physical and chemical properties, as well as sensitivity and selectivity to several types of contamination, including heavy metal ions. In this work, using the hydrothermal method, nanostructures of $\mathrm{ZnO}$ were synthesized in four different morphologies: nanorods, nanoneedles, nanotubes and nanoplates. To determine the peculiarities of adsorption for each morphology, a series of electrochemical measurements were carried out using these nanostructured $\mathrm{ZnO}$ coatings on the working electrodes, using aqueous solutions of $\mathrm{Pb}\left(\mathrm{NO}_{3}\right)_{2}$ and $\mathrm{Cd}\left(\mathrm{NO}_{3}\right)_{2}$ as analytes with different concentrations. It was found that the sensitivity of the resulting electrochemical sensors depends on the morphology of the $\mathrm{ZnO}$ nanostructures: the best results were achieved in the case of porous nanostructures (nanotubes and nanoplates), whereas the lowest sensitivity corresponded to $\mathrm{ZnO}$ nanorods with a large diameter (i.e., low surface-to-volume ratio). The efficiency of sedimentation is also related to the electronegativity of adsorbate: it has been shown that all observed $\mathrm{ZnO}$ morphologies exhibited significantly higher sensitivity in detecting lead ions compared to cadmium ions.
\end{abstract}

\section{Introduction}

Today, due to the rapid growth of industry and transport, the issues of environmental pollution by heavy metals, particularly by lead, mercury, cadmium and cobalt, are becoming more and more topical. Many metals form stable organic compounds that dissolve well in water and result in the migration of heavy metal ions in aquatic and terrestrial systems, thereby resulting in high levels of contamination $[1,2]$.
Lead is one of the most harmful heavy metals. Its presence is hazardous to the environment, it is toxic and carcinogenic, and it tends to accumulate in living organisms, where it replaces other elements in bones and tissues, and causes long-term poisoning [3-5]. That is why the creation of a sensor that could detect the presence of lead and other heavy ions, even in small quantities, is an important and topical task. 
$\mathrm{ZnO}$ nanostructures are promising candidates for use in such sensors. They are sensitive to various types of contamination, including almost all heavy metal ions and organic pollutants, and show very good adsorption results for the most hazardous ions $(\mathrm{Pb}, \mathrm{Cd}, \mathrm{Hg}$ ) [6-8]. Generally, $\mathrm{ZnO}$ is chemically inactive, so it will not become a secondary source of contamination. Furthermore, $\mathrm{ZnO}$ nanostructures can have various types of morphologies, thus making it possible to diversify the electrical and optical properties of the nanostructured layer for the particular application without changing the actual substance. Contrary to the case of needle-shaped nanostructures, other types of $\mathrm{ZnO}$ nanostructures have been less investigated, whereby research on such structures could open the possibilities for more potential applications.

Electrochemical methods such as cyclic voltammetry (CV), impedance spectroscopy (IS) and differential pulse voltammetry (DPV) are highly efficient in both qualitative and quantitative analysis of solutions [9-11]. These methods allow for the detection of hazardous chemicals even at very low concentrations [12-14]. Furthermore, combined with a sensor platform based on nanomaterials and nanostructures, these electrochemical methods contribute to the improvement of sensor performance in terms of sensitivity and specificity, primarily as a result of the large working electrode surface area, and consequently, large number of active links that raises the overall sorption capability.

Our research team performed a series of experiments aimed at determining the influence of hydrothermal growth conditions on the parameters of the obtained nanostructures, as well as obtaining $\mathrm{ZnO}$ nanostructures in various morphologies, such as $\mathrm{ZnO}$ nanoneedles, nanorods, nanotubes, nanoplates, etc. Also the purpose of our previous research was to identify optimal growth parameters for obtaining a homogeneous, dense, well-aligned nanostructured $\mathrm{ZnO}$ coating with good adhesion to hard surfaces. The results of the experiments are displayed and summarized in previously published articles [15-18].

This article is a follow-up study of previous research and describes the peculiarities of the practical application of previously obtained $\mathrm{ZnO}$ morphologies as a working electrode for the electrochemical sensor of heavy metal ions.

In this work, using the hydrothermal method, nanostructures of $\mathrm{ZnO}$ were synthesized in four different morphologies: nanorods (NRs), nanoneedles (NNs), nanotubes (NTs) and nanoplates (NPs). The samples described in this article were obtained using a preparation protocol based on previously recognized optimal hydrothermal growth parameters and are characterized by increased homogeneity, density, and orderliness in comparison with those obtained in early studies. To determine the peculiarities of adsorption for each morphology, a series of electrochemical measurements were carried out using these nanostructured $\mathrm{ZnO}$ coatings on the working electrodes using aqueous solutions of $\mathrm{Pb}\left(\mathrm{NO}_{3}\right)_{2}$ and $\mathrm{Cd}\left(\mathrm{NO}_{3}\right)_{2}$ as analytes with different concentrations.

\section{Experimental \\ Design and fabrication of the $\mathrm{ZnO}$ nanostructure-based electrochemical sensor}

Three morphologies of well-aligned one-dimensional $\mathrm{ZnO}$ nanostructures were selected for the experiment: nanorods, nanoneedles and nanotubes. The samples were prepared according to the following description.

Glass slides $(76 \times 26 \times 1 \mathrm{~mm})$ were precleaned via ultrasonication in aqueous solutions of $\mathrm{KOH}$ and $\mathrm{H}_{2} \mathrm{SO}_{4}$, followed by several rinses with deionized and distilled water, and finally dried in an electric oven at $90{ }^{\circ} \mathrm{C}$ to remove any residual water.

First, a $100 \mathrm{~nm}$ thick chrome layer was sputtered onto the glass substrate through a metal shadow-mask to provide electrical conductivity for further electrochemical measurements. The deposition was carried out with the LAB18 thin film deposition system (Kurt J. Lesker, USA) in DC magnetron sputtering mode. As a result, a set of electrodes consisted of four mutually separated planar elements, as illustrated in Figure 1.

All of the manipulations described below were carried out using a metal mask, which limits the flow of liquid around the sample and reduces the probability of grown particles to enter covered areas, providing the necessary selectivity of nanostructure growth only on the electrodes.

In the second step a temporary extra rubber sealing mask was applied and $\mathrm{Cr}$ electrodes were coated with a $\mathrm{ZnO}$ seed layer in order to provide adhesion of the nanostructured $\mathrm{ZnO}$ film to the glass surface, as well as epitaxial growth and the vertical alignment of nanostructures. It was prepared by dip coating using $5 \mathrm{mM}$ zinc acetate $\left(\mathrm{Zn}\left(\mathrm{O}_{2} \mathrm{CCH}_{3}\right)_{2}\right)$ solution in ethanol. The seed layer film was dried in a stream of dry nitrogen and thermally treated at $350{ }^{\circ} \mathrm{C}$ for $30 \mathrm{~min}$ in air, such that zinc acetate was completely converted into zinc oxide. Subsequently, the samples were slowly cooled to room temperature.

The nanostructured layer of the electrode was obtained by the hydrothermal synthesis method using an aqueous solution of zinc nitrate hexahydrate $\left(\mathrm{Zn}\left(\mathrm{NO}_{3}\right)_{2} \cdot 6 \mathrm{H}_{2} \mathrm{O} ; 99 \%\right.$ purity $)$ and hexamethylenetetramine (HMTA; $\mathrm{C}_{6} \mathrm{H}_{12} \mathrm{~N}_{4} ; 99 \%$ purity), where zinc nitrate is used as a source of $\mathrm{Zn}^{+}$ions; however, HMTA acts as a $\mathrm{pH}$ buffer by slowly releasing $\mathrm{OH}^{-}$ions. The 


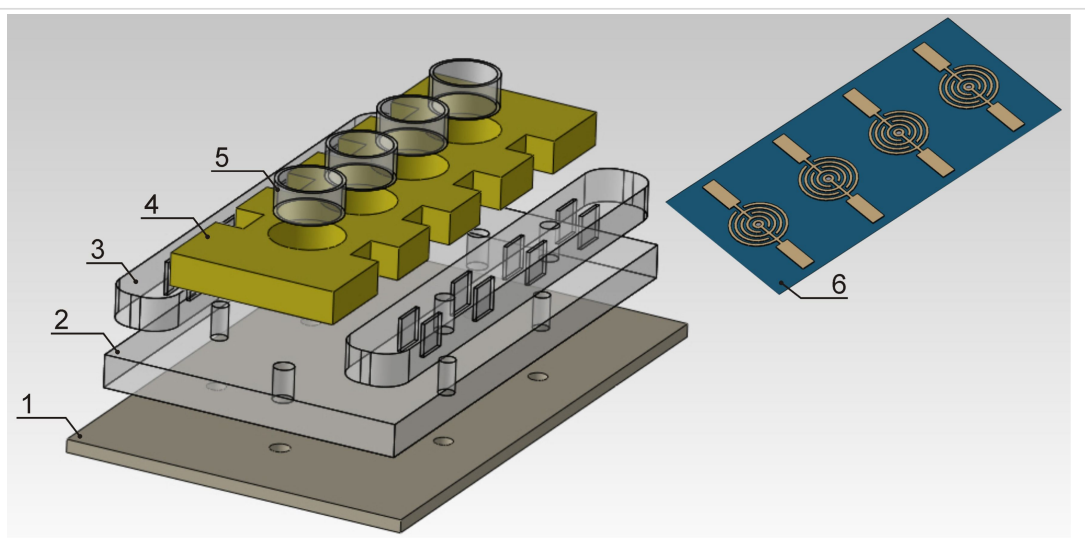

Figure 1: Structure diagrams of the electrical measurement cell and electrodes. Measurement cell consists of the following parts: a corps (1), an interlayer (2) with push-in contacts (3) and a sealing rubber mask (4) with replaceable plastic cylinders (5). The complete sample (6) consists of four electrodes, which allow four independent measurements to be consistently performed for solutions of different concentration or chemical composition.

decomposition rate of HMTA increases with the temperature of the growth solution. The growth of $\mathrm{ZnO}$ nanostructures occurs between $80-90{ }^{\circ} \mathrm{C}$, where the temperature is sufficient to produce the required amount of $\mathrm{OH}^{-}$ions from the HMTA solution in a relatively short period of time. In addition, the reaction does not occur instantaneously and not all of the components fall out as sediments. Furthermore, maintaining the temperature below the boiling point prevents any intense evaporation of the working solution, thereby allowing the experiment to be carried out without the use of an autoclave.

In order to grow uniform and vertically aligned $\mathrm{ZnO}$ nanorod arrays, the $\mathrm{ZnO}$ seed-coated glass substrate was immersed in an aqueous solution of $0.1 \mathrm{M} \mathrm{Zn}\left(\mathrm{NO}_{3}\right)_{2}+0.1 \mathrm{M} \mathrm{C}_{6} \mathrm{H}_{12} \mathrm{~N}_{4}$ in a glass vessel. The vessel was sealed with a lid and placed in oven maintained at $90{ }^{\circ} \mathrm{C}$ for three hours. Afterwards, the glass vessel was removed from the oven and cooled to room temperature. The sample was then removed from the solution, rinsed several times with distilled water and thermally treated at $90-110{ }^{\circ} \mathrm{C}$ for $30 \mathrm{~min}$ in order to remove the adsorbed water. For more detailed information see $[17,18]$.

$\mathrm{ZnO}$ nanotube arrays were obtained using a self-selective etching method based on selective dissolution of metastable $\mathrm{ZnO}$ planes with decreasing growth solution temperature, achieving a considerable $\mathrm{Zn}$-ion deficiency during the hydrothermal process [19-22]. The synthesis of the $\mathrm{ZnO}$ nanotubes was performed in a growth solution with the same chemical composition as for synthesis of nanorods: equimolar aqueous solution of $0.1 \mathrm{M} \mathrm{Zn}\left(\mathrm{NO}_{3}\right)_{2}+0.1 \mathrm{M} \mathrm{C}_{6} \mathrm{H}_{12} \mathrm{~N}_{4}$. The growth process was divided into two stages: growth of $\mathrm{ZnO}$ nanorods at $90{ }^{\circ} \mathrm{C}$ for three hours, and selective etching of $\mathrm{ZnO}$ nanorods at $50{ }^{\circ} \mathrm{C}$ for eighteen hours. After the growth process, the samples were rinsed several times and dried. More detailed information can be found in $[15,16]$.
The $\mathrm{ZnO}$ nanoneedles were synthesized by increasing the solution's $\mathrm{pH}$ level to form nanorod arrays with reduced diameters and higher aspect ratios. In order to maintain the chemical purity of the samples, the same chemical components were used for synthesis. The increase in $\mathrm{pH}$ was provided by not using an equimolar ratio of components, as in the previous cases, but instead, a 1:4 ratio with excess HMTA. An aqueous solution of $0.025 \mathrm{M} \mathrm{Zn}\left(\mathrm{NO}_{3}\right)_{2}+0.1 \mathrm{M} \mathrm{C}_{6} \mathrm{H}_{12} \mathrm{~N}_{4}$ was used to allow an increase in the $\mathrm{pH}$ of the working solution from 5.6 to 7.6.

In the time interval between the end of the growth process of nanostructures and the performance of electrochemical measurements, the electrodes were stored under ambient conditions.

\section{Characterization}

The surface morphology of the processed samples was investigated using a scanning electron microscope (SEM). The chemical composition of the samples was determined by an Oxford Instruments INCAx-act energy dispersive spectrometer (EDS) $\mathrm{X}$-ray detector attached to the SEM. To determine the structural and phase composition, the XRD spectra were recorded on a SmartLab $\mathrm{Cu} \mathrm{K} \alpha(\lambda=1.543 \AA)$ diffractometer (RIGAKU, Japan) with parallel beam geometry using an additional $\mathrm{Ge}(220) \times 2$ monochromator. The obtained X-ray pattern peaks were analysed by the PDXL program and compared to a database [23].

\section{Electrochemical studies}

The electrochemical measurements were performed on the Versa Stat 3 potentiostat supplemented by a laboratory-developed electrical measurement cell, which is consistent with the geometry of aforementioned samples (See (6) in Figure 1).The schematic diagram of the electrical measurement cell and the sample is shown in Figure 1. 
The reference cell consists of a corps (1), an interlayer (2) with push-in contacts (3) and a sealing system, which consists of chemically inert rubber seals (4) with holes of the same size as the electrode diameter and replaceable plastic cylinders (5). The sealing system prevents the solution from leaking, and allows for the application of the required amount of solution directly onto the electrodes. The cells were connected to a set of switches, whereby one can turn each of the four electrodes sequentially on and off. The measurements were performed at $20^{\circ} \mathrm{C}$ in the potential range of $-2 \mathrm{~V}$ to $+2 \mathrm{~V}$ at a scan rate of $0.5 \mathrm{Vs}^{-1}$.

For a qualitative analysis of the lead-ion deposition process, a series of cyclic voltammetry $(\mathrm{CV})$ measurements were carried out using aqueous $\mathrm{Pb}\left(\mathrm{NO}_{3}\right)_{2}$ solution with concentrations of $150 \mu \mathrm{M}, 300 \mu \mathrm{M}, 1.5 \mathrm{mM}$, and $3 \mathrm{mM}$ as a source of $\mathrm{Pb}^{2+}$ ions. In order to determine and compare the sensor sensitivity to other heavy metal ions, the experiment was repeated with cadmium, where the same concentration of aqueous $\mathrm{Cd}\left(\mathrm{NO}_{3}\right)_{2}$ solution was used as a source of $\mathrm{Cd}^{2+}$ ions. The aqueous solutions of analytes were freshly prepared prior to measurement.

In order to determine the sensor sensitivity threshold and quantify the change in ion concentration, a series of DPV measurements in $\mathrm{Pb}\left(\mathrm{NO}_{3}\right)_{2}$ aqueous solution at concentrations of $1.5 \mu \mathrm{M}, 3 \mu \mathrm{M}, 15 \mu \mathrm{M}, 30 \mu \mathrm{M}, 150 \mu \mathrm{M}$, and $300 \mu \mathrm{M}$ were performed. The same configuration of the cell was used in the measurements.

\section{Results and Discussion Characterization of the $\mathrm{ZnO}$ nanostructure-modified electrodes}

SEM images show that the resulting nanostructured coatings of all three morphologies were dense, homogeneous and of wellcontrolled shapes (see Figure 2).
The X-ray diffraction results revealed that the samples are crystalline with a hexagonal wurtzite structure. All XRD spectra show one dominant diffraction peak along the (002) plane, whereas the intensity of all the remaining peaks is negligible, confirming that the $\mathrm{ZnO}$ nanostructure arrays are well-aligned and have a strong preferential orientation in the (002) plane direction (Figure 3). Low levels of amorphous background reveal that the nanostructures have a high degree of crystallinity. In the case of the nanotubes, the intensity of the peak corresponding to the (002) plane is about four times lower than in the case of nanorods, indicating good efficiency of metastable plane etching.

The EDS spectrum confirms that the as-synthesized samples are chemically pure: no other elements other than $\mathrm{Zn}$ and $\mathrm{O}$ were detected.

\section{Cyclic voltammetry studies}

Prior to the CV measurements, $250 \mu \mathrm{L}$ of distilled water was pipetted into each cell, left for ten minutes to ensure the complete wetting of the nanostructured surface, and then the CV curves were recorded. It was determined that the CV curves for all four cells are very nearly identical. This allows for the exclusion of the effect of cell specificity on the subsequent measurement result.

Subsequently, the experiments were conducted by using aqueous $\mathrm{Pb}\left(\mathrm{NO}_{3}\right)_{2}$ solutions with concentrations of $150 \mu \mathrm{M}$, $300 \mu \mathrm{M}, 1.5 \mathrm{mM}$, and $3 \mathrm{mM}$. From the recorded CV curves, it can be seen that, in the case of nanorods, there is no significant difference with increasing concentration of $\mathrm{Pb}\left(\mathrm{NO}_{3}\right)_{2}-$ all curves almost overlap (Figure 4a).

In the case of nanotubes there are significant differences in the measured CV characteristics, as outlined in Figure 4b. There is
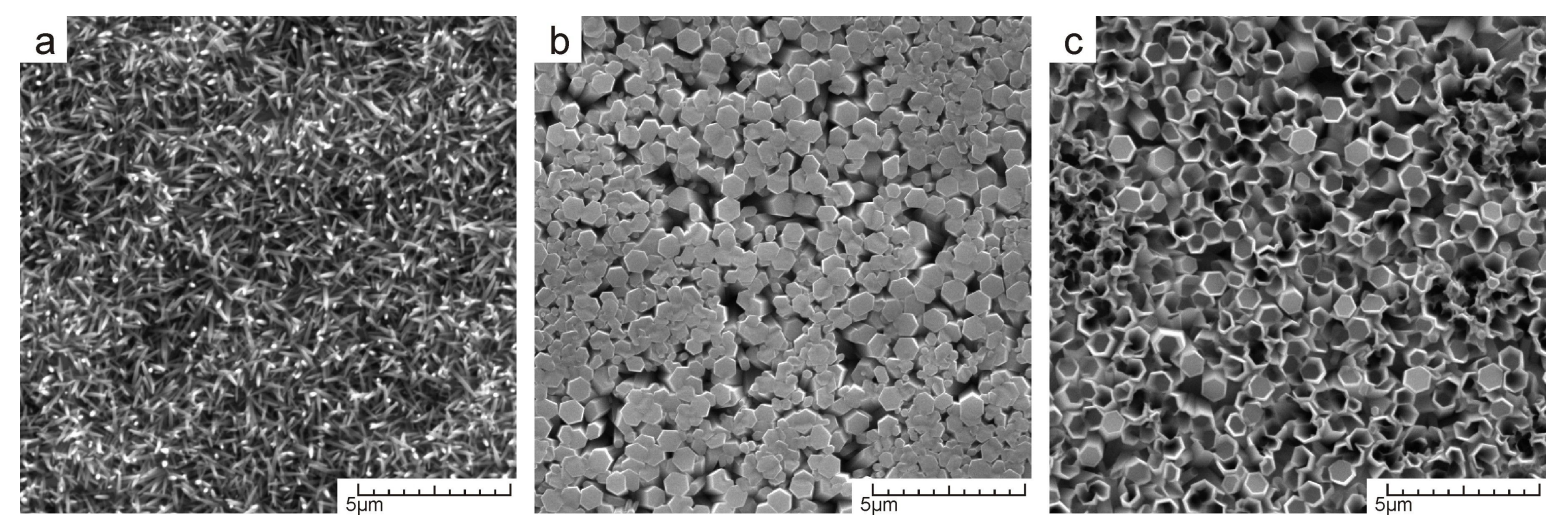

Figure 2: SEM images of as-synthesized $\mathrm{ZnO}$ nanostructure arrays: a) nanoneedles, b) nanorods [15], c) nanotubes [15]. 


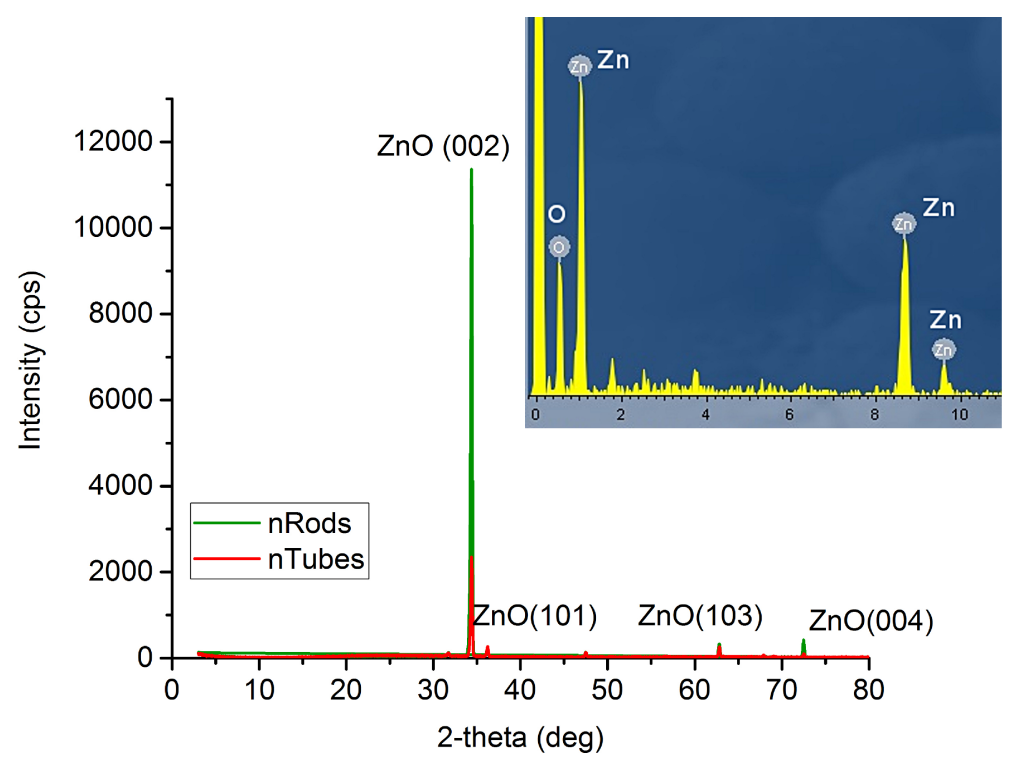

Figure 3: XRD pattern of $\mathrm{ZnO}$ nanorod and nanotube arrays. Inset: EDS spectrum of the as-synthesized samples.
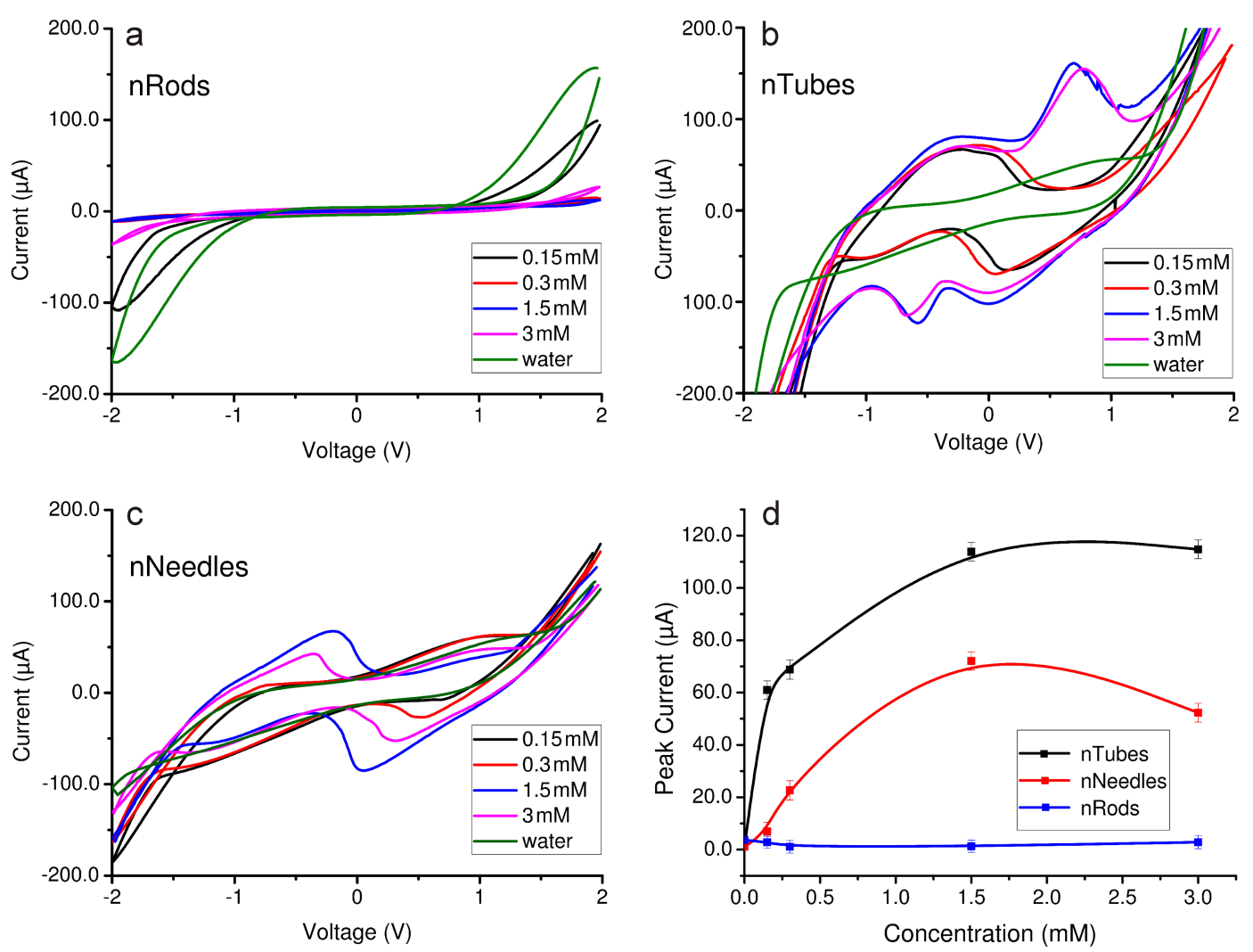

Figure 4: $\mathrm{CV}$ curves of aqueous $\mathrm{Pb}\left(\mathrm{NO}_{3}\right)_{2}$ solution on $\mathrm{ZnO}$ electrodes with different morphologies: (a) nanorods, (b) nanotubes, (c) nanoneedles, and (d) $\mathrm{CV}$ reduction peak dependence on $\mathrm{Pb}\left(\mathrm{NO}_{3}\right)_{2}$ concentration for all morphologies.

an asymmetry between the upper (oxidation) and the lower (reduction) components of the CV loop, which confirms that the process is irreversible: strong forces of attraction occur be- tween metal ions and the $\mathrm{ZnO}$ nanostructure surface, resulting in sedimentation containing a mixture of lead oxides and metallic lead. The XRD pattern and EDS spectra of the sedi- 
ment composition has been previously reported [16]. The formation of lead oxide is explained by the quasichemical Lewis interaction between lead ions and hydroxy groups on the $\mathrm{ZnO}$ surface as a result of coordination or covalent bonding. The presence of metallic lead in the sedimentation can be explained by the electrostatic attraction between $\mathrm{Pb}^{2+}$ and $\mathrm{ZnO}$ nanotube defects formed in large amount during the etching process.

The quantitative dependence of the concentration is also traceable: the size of the peak correlates with the concentration of the analyte. Duplex sets of CV curves are evident, in which the concentration differs by a factor of two and the duplex concentrations differ from each other by a factor of up to ten. At high concentrations, a second reduction peak occurs and the asymmetry of the CV loop becomes even larger and could be expressed not only in signal intensity, but also in the form of a curve. It confirms that the processes of ion sedimentation are irreversible.

In the case of nanoneedles, the asymmetry between oxidation and reduction components is less obvious (Figure 4c). The peak intensity is much lower than in the case of nanotubes. It may indicate that the bond strength between lead ions and the surface of $\mathrm{ZnO}$ is weaker. No proportional ratio of concentrations was observed.

Figure $4 \mathrm{~d}$ shows the dependence of the reduction peak maximum on the solution concentration, proving that nanotubes are more sensitive toward $\mathrm{Pb}^{2+}$.

A significant increase of the sensing properties of $\mathrm{ZnO}$ nanotubes in comparison with nanorods is confirmed by the determination of the capacity of static adsorption for $\mathrm{Pb}$ ions described in [16]. The higher value of this parameter also indicates an increase in the total number of bonds of lead ions to the surface of $\mathrm{ZnO}$ nanotubes. Calculations show that the static adsorption capacity of $\mathrm{ZnO}$ nanotubes and nanorods obtained under the same conditions is $611 \mathrm{mg} / \mathrm{g}$ and $256 \mathrm{mg} / \mathrm{g}$, respectively. The measurements were taken at room temperature using a $300 \mathrm{mM} / \mathrm{L}$ solution and immersing for $5 \mathrm{~min}$.

To study the adsorption of other ions, the experiment was repeated using the same concentrations of $\mathrm{Cd}\left(\mathrm{NO}_{3}\right)_{2}$ aqueous solutions. In general, $\mathrm{CV}$ curves for $\mathrm{Cd}\left(\mathrm{NO}_{3}\right)_{2}$ solutions had the same tendency as for $\mathrm{Pb}\left(\mathrm{NO}_{3}\right)_{2}$ solutions: $\mathrm{ZnO}$ nanorods exhibit no sensitivity to changes in solution concentrations (Figure 5).
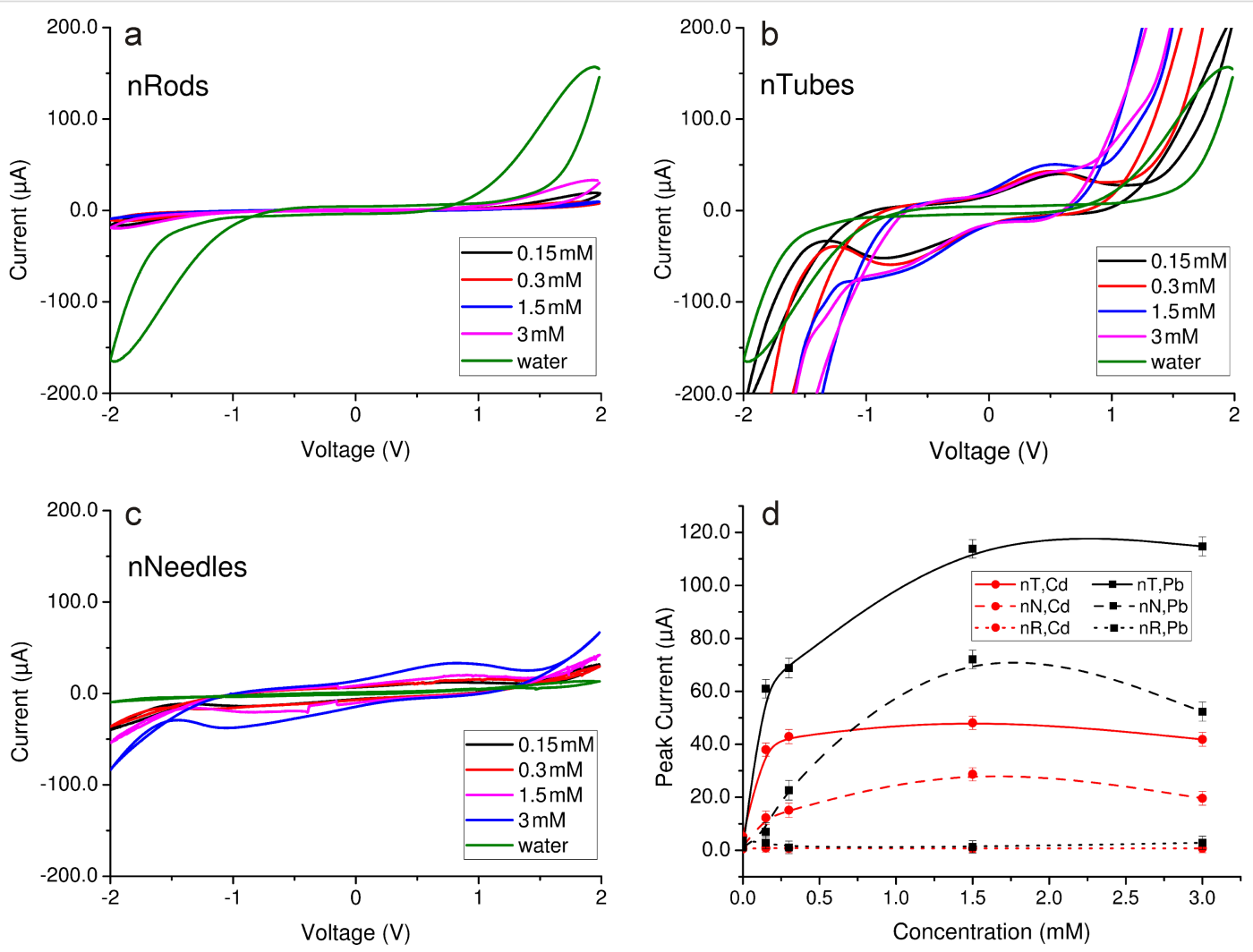

Figure 5: CV curves of aqueous $\mathrm{Cd}\left(\mathrm{NO}_{3}\right)_{2}$ solution on $\mathrm{ZnO}$ electrodes with different morphologies: (a) nanorods, (b) nanotubes, (c) nanoneedles and (d) $\mathrm{CV}$ reduction peak dependence on $\mathrm{Cd}\left(\mathrm{NO}_{3}\right)_{2}$ concentration for all morphologies and its comparison with the analogous curves for $\mathrm{Pb}\left(\mathrm{NO}_{3}\right)_{2}$ concentration (the data taken from Figure 4d). 
Slightly better results are observed in the case of $\mathrm{ZnO}$ nanoneedles, although the difference in concentration is much less noticeable than for the $\mathrm{Pb}\left(\mathrm{NO}_{3}\right)_{2}$ solution. $\mathrm{ZnO}$ nanotubes show the best results, similar to the case of the $\mathrm{Pb}\left(\mathrm{NO}_{3}\right)_{2}$ solution: duplex concentrations are observed, however, the differences are less noticeable than those of $\mathrm{Pb}\left(\mathrm{NO}_{3}\right)_{2}$.

If the reduction peaks of these two substances are compared (see Figure 5d), it can be seen that, for morphologies with higher sensitivity to both metal ions (i.e., nanotubes and nanoneedles), the current in the case of $\mathrm{Pb}\left(\mathrm{NO}_{3}\right)_{2}$ (black curves) is almost three times higher than that of the $\mathrm{Cd}\left(\mathrm{NO}_{3}\right)_{2}$ solution (red curves). This confirms a significantly better adsorption of $\mathrm{Pb}$ ions on the surface of $\mathrm{ZnO}$ than $\mathrm{Cd}$ ions.

The processes of ion sedimentation can be explained as follows. It is well known that the interaction of $\mathrm{ZnO}$ with airborne water or water vapour results in the formation of negatively charged hydroxy $\left(\mathrm{OH}^{-}\right)$groups, which can themselves act as new adsorption sites on the $\mathrm{ZnO}$ surface. The adsorption mechanism is based on the interaction of positively charged metallic ions with negatively charged hydroxy groups on the $\mathrm{ZnO}$ surface and, consequently, $\mathrm{Zn}-\mathrm{O}-\mathrm{H}$ bonds are replaced by $\mathrm{Zn}-\mathrm{O}-\mathrm{Cd}$ or $\mathrm{Zn}-\mathrm{O}-\mathrm{Pb}$ bonds $[24,25]$. Evidently, the better results in adsorption of $\mathrm{Pb}^{2+}$ compared to $\mathrm{Cd}^{2+}$ can be explained by the electronegativity of metals [25]. Since lead has a higher electronegativity than cadmium, it is more likely to be involved in the substitution reaction and forms stronger bonds with the $\mathrm{ZnO}$ surface. The Freundlich (multilayered) adsorption model is the result of a very strong interaction [26]. By contrast, $\mathrm{Cd}-\mathrm{O}$ bonds are much weaker than $\mathrm{Pb}-\mathrm{O}$ bonds, so in the case of cadmium, the Langmuir (monolayer) adsorption model is valid $[6,7,27]$. This is evidenced by lower sensor sensitivity to changes in concentrations of $\mathrm{Cd}\left(\mathrm{NO}_{3}\right)_{2}$ : the saturation occurs by filling all possible free bonds at low concentrations (which leads to the formation of monolayers; as a result, subsequent layers are not formed due to weak bonds.

Figure 5d shows that, in all cases of $\mathrm{ZnO}$ morphologies, the current of $\mathrm{Cd}$ ions saturated at low concentrations (up to $0.3 \mathrm{mM}$ ), and then remained nearly constant for increasing concentrations. Comparatively, in the case of $\mathrm{Pb}$ ions, the current saturated at much higher concentration of analyte (in the range of 1.5 to $2 \mathrm{mM}$ ). The reduction peak current for the highest concentration can be explained by mass crystallization in the solution, in parallel with the sorption process. It is the threshold above which crystallites of lead oxides become visible on the $\mathrm{ZnO}$ nanostructured surface by SEM.

In order to visually compare the sedimentation characteristics of both substances, the concentration of nitrate was increased 100 times (to $300 \mathrm{mM}$ ), which led to an intense crystallization process and the formation of visually appealing sediments.

As can be seen from Figure 6, for the same solution concentrations, $\mathrm{Pb}\left(\mathrm{NO}_{3}\right)_{2}$ forms well-developed crystallites of lead oxides mixture, whereas $\mathrm{Cd}\left(\mathrm{NO}_{3}\right)_{2}$ forms a very thin amorphous layer on the $\mathrm{ZnO}$ surface. The SEM images were recorded using secondary electrons, whose output depth is within the range of $1-10 \mathrm{~nm}$; the fact that the contours of the $\mathrm{ZnO}$ nanotubes (bright points) are easily visible through the film therefore indicates that the thickness of the $\mathrm{Cd}$ film does not exceed $10 \mathrm{~nm}$. It can be concluded that Cd sediments form a very thin layer of horizontally oriented crystallites. This confirms that bonds between $\mathrm{Cd}$ ions and the $\mathrm{ZnO}$ surface are much weaker than between cadmium ions that prevent the
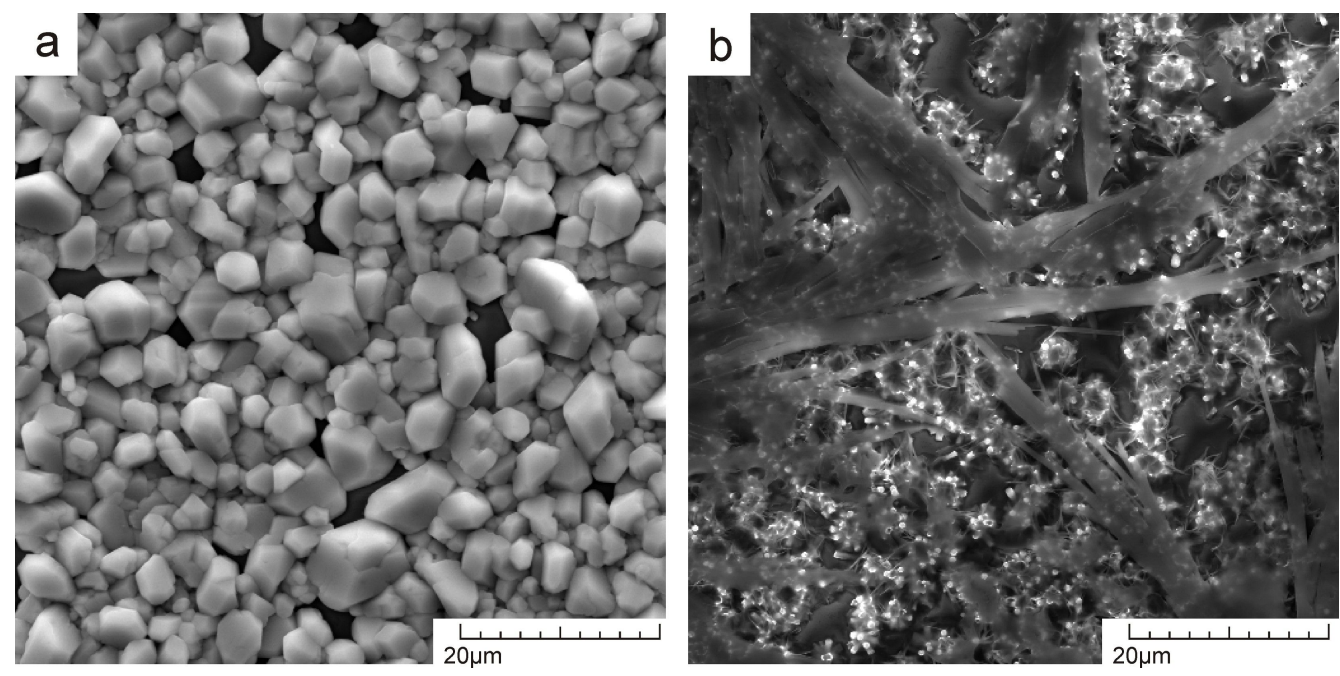

Figure 6: Sedimentation of (a) $\mathrm{Pb}\left(\mathrm{NO}_{3}\right)_{2}$ and (b) $\mathrm{Cd}\left(\mathrm{NO}_{3}\right)_{2}$ on the surface of $\mathrm{ZnO}$ nanotubes. 
rough $\mathrm{ZnO}$ surface to act as crystallization precursors in the heteroepitaxial growth process. In other words, particles will, with more probability, join an existing layer and increase its thickness rather than participate in the formation of a new precursor or the next layer.

The CV signal dependence on $\mathrm{ZnO}$ morphology can be explained as follows. There are two types of adsorption centres on $\mathrm{ZnO}$ nanostructure surfaces: on nonpolar lateral surfaces (such as the $(\overline{010})$ ) plane and its equivalent planes), and on polar surfaces that are largely intrinsic to structures with porous geometry and are associated with defects on metastable surfaces or on porous surfaces. The improvement of nanoneedle adsorption rates compared to nanorods can be attributed to an increase in the total lateral surface area, and as a result, an increase in the number of adsorption bonds [24,25]. Significant improvements in nanotube adsorption rates compared to similar diameter nanorods and nanoneedles are associated with both the increase in surface area (via the formation of a cavity) and the adsorption bonds due to surface defect sites. A large number of defects can be explained by the fact that, unlike nanorods and nanoneedles, which are formed in the hydrothermal growth process, nanotubes are formed in the etching process. Because of the remarkable deficiency of $\mathrm{Zn}$ ions, the aging process further suppresses the growth processes, and the probability of a new plane formation at the polar metastable plane (0002) is smaller than the probability of etching this plane by elements remaining in solution.

The role of adsorption bonds on surface defects and polar surfaces was tested using an additional morphology of adsorbent: $\mathrm{ZnO}$ nanoplates. This morphology was obtained by replacing HMTA with urea during the growth process, which resulted in inhibiting the growth of rods in the axial (c-axis) direction and stimulated growth in the lateral directions. As a result, the total surface area of (0002) planes increased, but the total surface area of lateral surfaces decreased.

Figure 7 confirms that, in the case of $\mathrm{ZnO}$ nanoplates, the measured $\mathrm{CV}$ curve shows even better results in the reduction component than in the case of nanotubes, thereby proving the effectiveness of porous structures: adsorption bonds, which are located on surface defect sites or on metastable polar planes, have a better ability to form compounds with adsorbate than bonds, which are located on nonpolar surfaces.

It follows from the experiments that, in concentrated solutions, the CV measurements clearly reflect the process quality, whereas in the low concentration range, the measurements show poor sensitivity.

\section{Differential pulse voltammetry studies}

In various papers, the DPV method was shown to be more sensitive and selective when compared to the CV method [2830]. Therefore, the experiment was repeated with this method for all morphologies of the $\mathrm{ZnO}$ nanostructures. As an analyte, an aqueous solution of $\mathrm{Pb}\left(\mathrm{NO}_{3}\right)_{2}$ was used. The maximum concentration was chosen 10 and 100 times lower than CV sensitivity threshold of $1.5-3 \mathrm{mM}$.

As shown in Figure 8, the DPV method is actually more sensitive than the $\mathrm{CV}$ method: using the same electrodes, it is possible to detect concentrations that are 100 times smaller than the CV sensitivity threshold.

With regards to the role of morphology in $\mathrm{ZnO}$ nanostructures on sensitivity, the DPV measurements presented the same trend as the CV measurements: nanotubes, followed by nanoneedles,
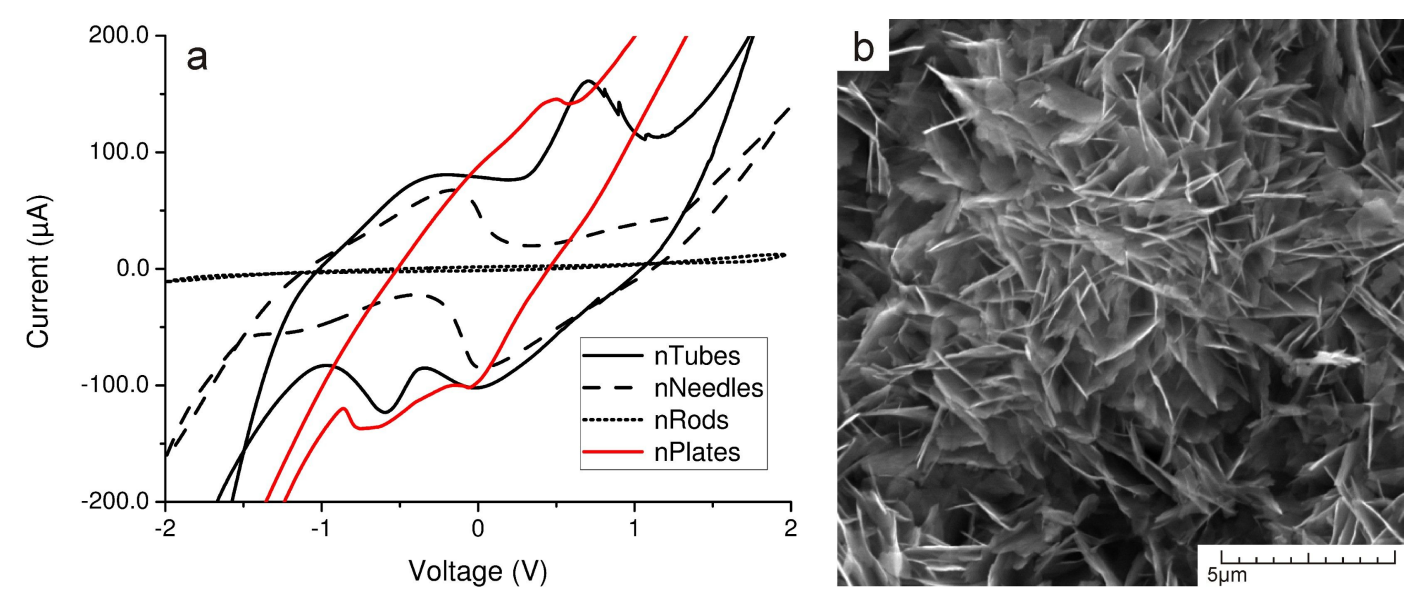

Figure 7: (a) CV curve for the concentration of $1.5 \mathrm{mM} \mathrm{Pb}\left(\mathrm{NO}_{3}\right)_{2}$ on $\mathrm{ZnO}$ nanoplates (red) compared to the previously used $\mathrm{ZnO}$ morphologies (black curves); (b) SEM image of as-synthesized $\mathrm{ZnO}$ nanoplates. 

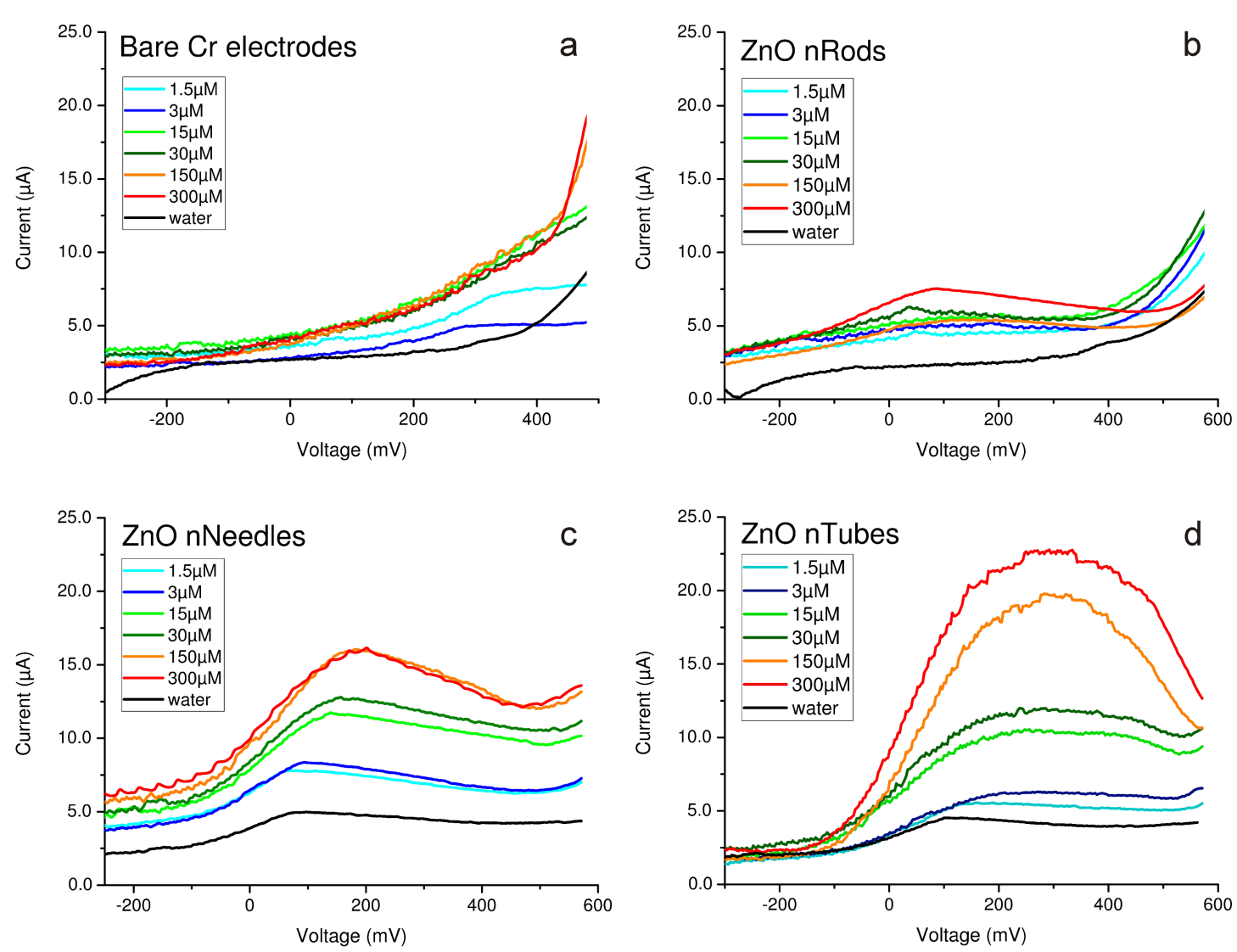

Figure 8: DPV curves for different $\mathrm{ZnO}$ morphologies: (a) untreated $\mathrm{Cr}$ electrodes, (b) nanorods, (c) nanoneedles and (d) nanotubes. As an analyte, a solution of $\mathrm{Pb}\left(\mathrm{NO}_{3}\right)_{2}$ at concentration of $1.5 \mu \mathrm{M}$ to $300 \mu \mathrm{M}$ was used.

show the best results; the lowest sensitivity was observed on electrodes coated by nanorods. The current peaks did not appear on the untreated $\mathrm{Cr}$ electrodes; furthermore, the signal dependence on $\mathrm{Pb}\left(\mathrm{NO}_{3}\right)_{2}$ concentration was not observed. In the case of nanostructured electrodes, there is a strong dependence of the signal on analyte concentration (Figure 8): concentration duplexes were observed not only in the case of nanotubes, as was observed in CV measurements (Figure 4), but also in the cases of nanoneedles and even for nanorods.

\section{Conclusion}

Overall, it can be concluded that the CV technique is suitable for qualitative process monitoring, but the DPV measurements are more suitable for quantitative analysis, where it is necessary not only to determine the presence of analyte in solution, but also the accurate concentration of analyte. The DPV technique also showed better sensitivity in the case of low analyte concentrations: it allows for the detection of concentrations of $\mathrm{Pb}\left(\mathrm{NO}_{3}\right)_{2} 100$ times lower than the $\mathrm{CV}$ technique.

The effects of $\mathrm{ZnO}$ nanostructure morphology on the sensor sensitivity were also investigated. There is a clear tendency towards enhancing the intensity of the measured signal by increasing the surface area of working electrodes. In all measurements, nanotubes exhibited significantly higher sensitivity than nanorods and nanoneedles. This confirms that adsorption bonds associated with defect states contribute more to the process than the adsorption bonds, which are located on the nonpolar, side surfaces. This fact was also confirmed by an additional experiment on $\mathrm{ZnO}$ nanoplates.

The effectiveness of sedimentation is directly related to the electronegativity of the adsorbate: substances with higher electronegativity form stronger bonds with the $\mathrm{ZnO}$ surface and exceed the monolayer range. This was supported by the fact that a significantly better adsorption of lead ions was observed compared to cadmium ions on the surface of $\mathrm{ZnO}$ nanostructures. This tendency was observed for all morphologies across all concentrations of analyte.

In general, it can be concluded that $\mathrm{ZnO}$ nanostructures with porous morphology can be used as an effective heavy metal ion sensor on the one hand, and an effective adsorbent of these ions on the other. 


\section{Acknowledgements}

This research was supported by ERAF Project No.1.1.1.1/16/A/ 001 "Development of the analytical molecular recognition device based on the nanostructures of metal oxides for biomolecules detection".

\section{ORCID ${ }^{\circledR}$ iDs}

Marina Krasovska - https://orcid.org/0000-0002-5959-0442 Vjaceslavs Gerbreders - https://orcid.org/0000-0003-3385-4507 Irena Mihailova - https://orcid.org/0000-0002-1563-2209 Andrejs Ogurcovs - https://orcid.org/0000-0001-7211-8479 Eriks Sledevskis - https://orcid.org/0000-0002-2921-6361 Andrejs Gerbreders - https://orcid.org/0000-0002-1365-4391 Pavels Sarajevs - https://orcid.org/0000-0002-4950-3819

\section{References}

1. Tchounwou, P. B.; Yedjou, C. G.; Patlolla, A. K.; Sutton, D. J. Heavy Metals Toxicity and the Environment. In Molecular, Clinical and Environmental Toxicology; Luch, A., Ed.; Experientia Supplementum, Vol. 101; Springer: Berlin, Germany, 2012; pp 133-164. doi:10.1007/978-3-7643-8340-4_6

2. Singh, S.; Barick, K. C.; Bahadur, D. Nanomater. Nanotechnol. 2013, 3, 20. doi:10.5772/57237

3. Rasmussen, K. L.; Skytte, L.; Jensen, A. J.; Boldsen, J. L. J. Archaeol. Sci.: Rep. 2015, 3, 358-370. doi:10.1016/j.jasrep.2015.06.021

4. Pemmer, B.; Roschger, A.; Wastl, A.; Hofstaetter, J. G.; Wobrauschek, P.; Simon, R.; Thaler, H. W.; Roschger, P.; Klaushofer, K.; Streli, C. Bone 2013, 57, 184-193. doi:10.1016/j.bone.2013.07.038

5. Rahman, M. M.; Khan, S. B.; Asiri, A. M.; Marwani, H. M.; Qusti, A. H. Composites, Part B 2013, 54, 215-223. doi:10.1016/j.compositesb.2013.05.018

6. Venkatesham, V.; Madhu, G. M.; Satyanarayana, S. V.; Preetham, H. S. Procedia Eng. 2013, 51, 308-313. doi:10.1016/j.proeng.2013.01.041

7. Khan, S. B.; Rahman, M. M.; Marwani, H. M.; Asiri, A. M.; Alamry, K. A. Nanoscale Res. Lett. 2013, 8, 377. doi:10.1186/1556-276x-8-377

8. Anjum, M.; Miandad, R.; Waqas, M.; Gehany, F.; Barakat, M. A. Arabian J. Chem., in press. doi:10.1016/j.arabjc.2016.10.004

9. Li, G.; Miao, P. Theoretical Background of Electrochemical Analysis. Electrochemical Analysis of Proteins and Cells; Springer Briefs in Molecular Science; Springer: Berlin, Germany, 2013; pp 5-18. doi:10.1007/978-3-642-34252-3_2

10. Wang, H. Mod. Appl. Sci. 2010, 4, 116-121. doi:10.5539/mas.v4n4p116

11. Wei, Z.; Yang, Y.; Wang, J.; Zhang, W.; Ren, Q. J. Food Eng. 2018, 217, 75-92. doi:10.1016/j.jfoodeng.2017.08.005

12. Ghodsi, J.; Rafati, A. A. J. Electroanal. Chem. 2017, 807, 1-9. doi:10.1016/j.jelechem.2017.11.003

13. Lu, Y.; Liang, X.; Niyungeko, C.; Zhou, J.; Xu, J.; Tian, G. Talanta 2018, 178, 324-338. doi:10.1016/j.talanta.2017.08.033

14. Bansod, B. K.; Kumar, T.; Thakur, R.; Rana, S.; Singh, I. Biosens. Bioelectron. 2017, 94, 443-455. doi:10.1016/j.bios.2017.03.031

15. Krasovska, M.; Gerbreders, V.; Paskevics, V.; Ogurcovs, A.; Mihailova, I. Latv. J. Phys. Tech. Sci. 2015, 52, 28-40. doi:10.1515/lpts-2015-0026
16. Krasovska, M.; Gerbreders, V.; Tamanis, E.; Gerbreders, S.; Bulanovs, A. Latv. J. Phys. Tech. Sci. 2017, 54, 41-50. doi:10.1515/lpts-2017-0005

17. Gerbreders, V.; Sarajevs, P.; Mihailova, I.; Tamanis, E. Latv. J. Phys. Tech. Sci. 2015, 52, 20-27. doi:10.1515/lpts-2015-0025 18. Mihailova, I.; Gerbreders, V.; Bulanovs, A.; Tamanis, E.; Sledevskis, E.; Ogurcovs, A.; Sarajevs, P. Controlled growth of well-aligned $\mathrm{ZnO}$ nanorod arrays by hydrothermal method. In Proceedings Volume 9421, Eighth International Conference on Advanced Optical Materials and Devices (AOMD-8), Eighth International Conference on Advanced Optical Materials and Devices (AOMD-8), Riga, Latvia, Oct 22, 2014; 94210A. doi:10.1117/12.2083960

19. Xi, Y.; Song, J.; Xu, S.; Yang, R.; Gao, Z.; Hu, C.; Wang, Z. L. J. Mater. Chem. 2009, 19, 9260-9264. doi:10.1039/b917525c

20. Chae, K.-W.; Zhang, Q.; Kim, J. S.; Jeong, Y.-H.; Cao, G. Beilstein J. Nanotechnol. 2010, 1, 128-134. doi:10.3762/bjnano.1.15

21. Roza, L.; Rahman, M. Y. A.; Umar, A. A.; Salleh, M. M. J. Alloys Compd. 2015, 618, 153-158. doi:10.1016/j.jallcom.2014.08.113

22. Wang, H.; Li, G.; Jia, L.; Wang, G.; Tang, C. J. Phys. Chem. C 2008, 112, 11738-11743. doi:10.1021/jp803059k

23. Altomare, A.; Camalli, M.; Cuocci, C.; Giacovazzo, C.; Moliterni, A.; Rizzi, R. J. Appl. Crystallogr. 2009, 42, 1197-1202. doi:10.1107/S0021889809042915

24. Cai, W.; Duan, G.; Li, Y. Structurally Enhanced Adsorption Performances for Environment. Hierarchical micro/nanostructured materials: fabrication, properties, and applications; CRC Press: Boca Raton, FL, U.S.A., 2014; pp 141-184. doi:10.1201/b17075-8

25. Wang, X.; Cai, W.; Liu, S.; Wang, G.; Wu, Z.; Zhao, H. Colloids Surf., A 2013, 422, 199-205. doi:10.1016/j.colsurfa.2013.01.031

26. Zolfaghari, G.; Esmaili-Sari, A.; Anbia, M.; Younesi, H.; Ghasemian, M. B. Int. J. Environ. Sci. Technol. 2013, 10, 325-340. doi:10.1007/s13762-012-0135-6

27. Wang, X.; Guo, Y.; Yang, L.; Han, M.; Zhao, J.; Cheng, X. J. Environ. Anal. Toxicol. 2012, 2, 154. doi:10.4172/2161-0525.1000154

28. Salariya, K.; Umar, A.; Kansal, S. K.; Mehta, S. K. Sens. Actuators, B 2017, 241, 276-284. doi:10.1016/j.snb.2016.10.064

29. Ruslan, N. I.; Lim, D. C. K.; Alang Ahmad, S. A.; Abdul Aziz, S. F. N.; Supian, F. L.; Yusof, N. A. J. Electroanal. Chem. 2017, 799, 497-504. doi:10.1016/j.jelechem.2017.06.038

30. Choudhary, Y. S.; Jothi, L.; Nageswaran, G. Electrochemical Characterization. In Spectroscopic Methods for Nanomaterials Characterization; Thomas, S.; Thomas, R.; Zacchariah, A. K.; Mishra, R. K., Eds.; Elsevier: Amsterdam, Netherlands, 2017; Vol. 2, pp 19-54. doi:10.1016/b978-0-323-46140-5.00002-9 


\section{License and Terms}

This is an Open Access article under the terms of the Creative Commons Attribution License

(http://creativecommons.org/licenses/by/4.0). Please note that the reuse, redistribution and reproduction in particular requires that the authors and source are credited.

The license is subject to the Beilstein Journal of Nanotechnology terms and conditions:

(https://www.beilstein-journals.org/bjnano)

The definitive version of this article is the electronic one which can be found at:

doi:10.3762/bjnano.9.227 